\title{
Situated Encounters with Socially Engaged Art in Community-Based Design
}

\author{
Rachel Clarke ${ }^{1}$ \\ Open Lab ${ }^{1}$ \\ Newcastle University \\ \{Rachel.Clarke\} \{P.C.Wright\} \\ @newcastle.ac.uk
}

\author{
Jo Briggs ${ }^{2}$ \\ Ann Light ${ }^{3}$ \\ Media \& Communication Design \\ Northumbria University ${ }^{2}$ \\ Newcastle-upon-Tyne \\ Jo.Briggs@northumbria.ac.uk
}

\author{
Peter Wright ${ }^{1}$ \\ School of Engineering \& \\ Informatics $^{3}$ \\ University of Sussex \\ Ann.Light@sussex.ac.uk
}

\begin{abstract}
With the increased relevance of digital technologies in civil life comes the challenge of how to design research for citizen engagement. Drawing from three reflexive case studies presenting socially engaged arts (SEA) projects, we describe how, as artists, collaborators and researchers, we engaged in socially inclusive community-based projects. We argue that our roles required us to be both flexible and to adopt critical openness in practices of collaborative social facilitation. We conclude with insights to inform community-based research and enable nurturing and inclusive engagement in research design for the exploration of near-future digital technologies.
\end{abstract}

\section{Author Keywords}

Socially Engaged Art; community-based design; participation; civic engagement; social change

\section{INTRODUCTION}

Community-based design research is increasingly understood as complex, requiring commitments that that go beyond "formal methods" $[10,16,18,45,46]$. As researchers we adopt multiple approaches taking on flexible and responsive roles, sensitively adapting to situations as our understanding and relationships change during the process $[22,31,36]$. In community-based participatory and action research, involving artists is an increasingly common tactic used to open up alternative lines of inquiry, or build community confidence [20]. Artists develop approaches to envision alternative imaginaries, often overlooked in conventional research focused on linguistic forms of expression and representation [30]. The use of performance, photography and video for instance, can help elicit rich accounts of people's experience, and also make more explicit practitioners' implicated roles [4,24,27].

Permission to make digital or hard copies of part or all of this work for personal or classroom use is granted without fee provided that copies are not made or distributed for profit or commercial advantage and that copies bear this notice and the full citation on the first page. Copyrights for thirdparty components of this work must be honored.

Copyright is held by the owner/author(s).

DIS 2016, June 04-08, 2016, Brisbane, QLD, Australia

ACM 978-1-4503-4031-1/16/06.

http://dx.doi.org/10.1145/2901790.2901882

\section{(c) (i)}

This work is licensed under a Creative Commons Attribution International 4.0 License
In HCI and related research there is increased interest in design involving communities in sustained acts of civic engagement $[45,46]$. We argue that wider awareness of socially engaged arts (SEA) practitioner roles can be of benefit and part of our contribution is to help acknowledge this and open up further discussion. SEA has emerged within HCI over the past decade [13] facilitated by its orientation towards social change, social justice [12,34], sustainability $[8,15]$, inclusion and participation [48]. And yet, while practices have been adopted in design research they still remain largely under-acknowledged.

We believe that we are in a privileged position to contribute by articulating the complexities and intricacies of community engagement from our own experiences. Our authorship consists of HCI researchers with backgrounds in SEA practice $[6,12]$; and well-established HCI academics who have worked extensively with SEA practitioners [33, 34,35,37] and drawn conceptual and theoretical insights from such work [38,51]. However, we also advocate for additional work to build and sustain more equitable and inclusive relationships between researchers and communities. This, we feel is particularly important where research is motivated by a desire to bring about "realworld" social change, but also requires caution and shared responsibility in accounting for the social and material consequences that may occur, when designing and using digital technologies.

In this paper we discuss how we position ourselves within community-based projects and how these positions both influence and are influenced by our process. As researchers we typically work with a multiplicity of narratives to engage with the perspectives of those with whom we work, while also articulating our own positions [3,22,31,43]. The inherently durational aspect of our work with and within communities is an important feature [10,45]; our positions are situated not just in place but also time, and subject to change. With a growing shift from designing for discrete interactive systems to designing for their extensive use across social, cultural and civil life $[1,26]$ the insights we contribute have wide applicability to supporting community-based HCI design research practices.

Our contribution is centered on three reflexive accounts of discrete projects that we have developed since 2000. Our 
descriptions are detailed to foreground our roles and commitments to working as and working with SEA practitioners and researchers. By reflecting back we reveal how we performed multiple overlapping practitionerresearcher identities to ask: What were the motivations and expectations at the outset of what often became extended and sometimes-intense forms of engagement? What anticipated and unexpected roles did we adopt as the projects evolved? How did our identities evolve over time?

We sketch out the necessarily complex personas and entangled relations that were created through processes of working with communities. And we extend - and also trouble $[9,21]$ - existing vocabulary for researcher identities and roles within community-based design. We present our case studies as sensitizing strategies [29] to provoke and open up discussion on some of the intricacies of designing and facilitating design research. We argue this way of working necessitates an ongoing commitment to critical openness, to work with uncertainty and a willingness to submerge ourselves and make sense of complexity [29].

\section{SOCIALLY ENGAGED ART IN HCI}

Arts-based practices within HCI research have made significant contributions to both the understanding of people's experiences with technology and to the design of aesthetics for digital interaction. As a subset of fine arts practice, SEA is a "process-based approach" [4] in that it is grounded on the "facilitation of dialogue among diverse communities' [27 p.153] rather than on artifacts or exhibitions. Drawing from traditions of performance and activism [5,19,23], SEA within HCI has so far primarily been employed around issues of environmental sustainability $[8,15]$.

Valuable theoretical insights from SEA and applied in HCI, have shown how researchers can support collaborative investigation of the very conditions in which problems are defined, technology is developed and/or used, and knowledge produced. We find these theoretical arguments compelling as they question what it means to "do good", or attempt to mobilize social change, or at least improve "real world" situations through research. Further, these insights attend to how we frame our research objectives by shifting the focus of design from tangible artifacts to the processes and practices of research, collaboration, facilitation and knowledge production. However, much of the existing work has focused on rhetorical reflections of brief episodes in time, and rarely accounts for more durational and relational aspects of engagement, or the shifting roles that researchers enact to address challenges and tensions encountered along the way.

Within the arts, practitioners are typically experienced in public engagement and its facilitation. We believe that there is value in critically reflecting upon what it is in particular that SEA practitioners do. Our aim is to exemplify and tease out some of these roles in relation to the durational complexities and social and political intricacies that community-based research often involves.

\section{Between community and researcher identities}

The community-based informatics and design literatures frequently outline the importance of researchers familiarizing themselves with particular community identities to enable meaningful participation $[10,16]$. This is considered important, so as not to conceptualize communities as homogenous and harmonious wholes and rather to understand the informal ways that relationships within communities are formed. However, researchers' roles and positions are rarely discussed and critically questioned in relation to how their values and assumptions inform the construction of research sites or framing of research questions. The two areas that have articulated this most fully are Action Research and Participatory Design.

Hayes describes how research is never 'value neutral' in that researchers bring personal values into the field [22]. She articulates these in terms of researchers becoming 'friendly outsider(s)' who work in close proximity to the community as "ccoaches" skilled at opening up lines of communication and facilitating research activities with community partners' [p.8]. This is accompanied by recognition of particular expertise in and awareness of what digital technology is available and appropriate for a particular situation.

In Participatory Design, Light and Akama [36] highlight the emotional acuity required in facilitation roles, particularly those to support design research for community safety. Light and Akama highlight the importance of creating safe spaces for conflict and difference where people could feel comfortable sharing difficult experiences. Facilitating such spaces required additional time in working with participants' stories of loss and anger, before issues of safety could even be approached - an unanticipated but vital step in the design work.

In an eloquent exposition of researcher roles, Le Dantec and Fox [31] describe how these changed to help manage a complex research agenda over time. Their in-depth account from an under-reported community researcher perspective, advocates that the researcher step back from the work of designing digital interaction and instead focus on the design of the research goals and objectives with the community. Their description articulates complex work that necessarily precedes the design of any digital infrastructure or artifacts. This is not just about how researchers gain access to and/or become part of a community; but recognition of constant navigation of multiple and often conflicting identities. Le Dantec and Fox usefully highlight how these roles are not just positions that as researchers we define ourselves, but roles that are negotiated within and sometimes ascribed by the communities with whom we work. If we become a confidant this is because someone values us in this way. 
We applaud the value of feminist scholarship to the design community in advocating for greater transparency in our reporting of values, positionality and reflexivity $[3,21,43]$. Indeed, hiding our positions and decision-making processes can disguise differences in power and influence. Yet, as Le Dantec and Fox [31] and Light and Akama [36] show, researchers' positions can change when their initial approaches do not fit with the aims or sensibilities of the community, or when different issues emerge. Positions, roles and identities are also open to others' interpretation and can mean different things to different people, requiring continual questioning and responsiveness [43].

It is therefore useful here to consider the limits of being able to know, and fully account for our positions with certainty. Feminist scholars have also argued that aiming for comprehensive transparency in reflexivity is bound to fail [43]. It is important to recognize the situated nature and partiality of knowledge production that does not claim complete transparency. Situatedness is never, in effect, completely knowable and reportable. In this sense researchers are always working with a shifting self, articulated through specific and ongoing social interactions, informed by the research inquiry and ongoing relationships with people. It is only through enacting and performing roles through with others that the complexity and uncertainty of identity becomes (partially) recognizable and understood [9].

\section{Between art theory and practice}

SEA literature offers further valuable perspectives on such negotiations to community-based design and associated research. The concept of dialogical aesthetics was adopted by art historian Grant Kester [27] as a way of characterizing SEA as emerging through direct community action or intervention. Kester argues that empathic listening within forms of communicative exchange is where value is created [27 p.90] - as opposed to it being manifest in a tangible artifact or other output. Communication here is described as particular and unique, in that these relational processes enable sharing of and reflection upon personal biographies in processes that are both specifically situated and yet open to change. A dialogical aesthetic then is an approach, a way of working in which practitioners and those involved can appreciate the process of engagement, from different centers of value. Kester describes this as 'performative' in that 'the identity of the artist and those involved is produced through situational encounters', rather than through forms of performativity associated with theatricality or spectacle [27 p.95].

In a similar vein, theorists such as Claire Bishop identify the value of SEA practices as working with and accounting for the complexity of social relations, the tangled knots of 'engagement, affect, inequality' [4 p.39]. Rather than highlighting empathic dialogue, Bishop underlines the 'undecidability' of aesthetic experience as an important characteristic [4 p.27]. She argues that this is not just achieved through rational verbal argumentation, but embedded through the affective experience of working with uncertainty and contradiction, collaboratively. Bishop's account includes a useful reflection on the multiplicity of people involved in artworks, how the projects are conceived, funded, align or contradict with the diverse values of those who participate or facilitate their production. Creating such events requires approaches to gathering people and resources together. The role of the artist in this sense is therefore decentralized as controlling the action by highlighting a meshwork of actors taking on roles ordinarily not associated with creative practice.

From a SEA practitioner perspective, Pablo Helguera [23] further highlights that artists' roles may be much more fluid within socially engaged work, balancing between project management, social work and protest. This can create feelings of vulnerability for all those involved, not least, in how artists' roles may be perceived by others. There is constant negotiation of roles and commitments within a community. Artists may indeed subscribe to values, such as 'the betterment of humanity ... social justice, the defense of human dignity and worth, and the strengthening of human relationships' [23 p.35]. However, what distinguishes them in their role is a 'critical self reflexive dialogue' [p.35] that encourages reflection on these values and concerns, through practices of working with people. The emphasis here is placed less on extremes - of confrontation and harmony and more on practices of listening to a community of narrators and translators. Those involved may 'willingly engage in a dialogue from which they extract enough critical and experiential wealth to walk away feeling enriched, perhaps even claiming some ownership of the experience or the ability to reproduce it with others' [p. 23]. Helguera highlights how SEA practitioners often have an overt agenda which emphasizes developing a 'platform or a network for the participation of others, so that the effects of the project may outlast its ephemeral presentation' [p.23]. So while SEA practitioners may not always stay closely involved in a project, they may contribute to mobilizing certain forms of action, awareness or resources that continue beyond their immediate involvement.

\section{CASE STUDIES}

We now sketch our roles in three case studies by presenting reflexive first person perspectives, gained from our experiences facilitating community-based projects. We do this as a sensitizing strategy [29] to illustrate the specificities of our positions as artist-practitionerresearchers. The case studies have been selected because they were all informed by SEA practices but show a spectrum of positions working across different contexts and timescales. Furthermore we chose them because we have intimate knowledge of how they began and felt we could contribute details of our changing positions across time.

The first project Weird View $[6,40]$ was completed 15 years ago by second author, Jo Briggs, in collaboration with artist 
Valentina Nisi and the residents of a terrace of houses in County Dublin. This work was not developed as HCI research but as a collaborative interactive social history artwork for exhibition, but nonetheless provides insights on relationships and concepts for digital media were developed. Our second project DemTech [33,34,35,37] began in 2007, led by third author Ann Light, and featured researchers with an interest in arts-based practice and SEA artists collaborating in a community-based project with older adults. It has since grown into a new community initiative for sustainable energy. More recent and continuing interdisciplinary HCI design research Photoparshiya $[11,12,14]$ began in 2011 initiated by first author, Rachel Clarke, working as an artist with a background in SEA and new to HCI research. This project enabled the continuation of a collaborative community-based research initiative with an international women's center. We report the cases in the first person, working from within, and using our combined reflections to critically frame and identify our changing roles.

As an organizational device, we move chronologically through the three projects and provide a brief overview of each, how we began them, how we developed working relationships and how we left these relationships or kept in touch. This allows us to reflect specifically on durational aspects of our positions and roles within the work, while recognizing the changes that time has brought in the way of new technical opportunities and challenges. For the purposes of this paper we focus on our roles and therefore do not detail our methods or include perspectives of those we worked with as these are more fully discussed in prior work detailed above.

\section{Weird View}

Weird View was a community digital art project produced as the "final exhibition" of a master's course at Trinity College Dublin, where, after 10 years as a visual artist, I was undertaking training in multimedia systems. The brief was to "collaboratively develop" an interactive artwork. I was keen to extend collaboration beyond the 30 multidisciplinary postgraduates and involve people as coproducers of the artwork drawing inspiration from similar community broadcast work of its time [47].

\section{Getting Started (partner-friend-artist-computer postgrad)}

Weird View was born tangentially to this institutional process and came about through existing close ties and circumstances relating to my partner. At a family funeral in Lucan, Co. Dublin, he was reunited with four siblings from across three continents. They all met, along with cousins and old friends, and at the reception - where the stories flowed along with the drink. It was here that the idea to capture childhood reminiscences emerged. The timing and open nature of the family project enabled and demanded its immediate development, to involve some of those who were only around for a few days [6].
I began unobtrusively, researching by word-of-mouth and collecting the names of all the residents of a terrace of 20 cottages over living memory. This helped to capture people's interest and paper lists were passed around the village and annotated. Meanwhile the project revealed its potential for the proposed exhibition and Trinity postgraduate and artist Valentina Nisi, came on board. Meanwhile my partner and his closest familial ties were key, in not only contributing further stories but also by enabling and fast-forwarding connections more widely, and engendering everyone's trust in me.

In her work on site-specific artwork and situated identities, Mwon Kwon says that the most meaningful participation builds on existing ties to a particular community or friendship group [28]. My partner had lived on the terrace all of his life and he was pivotal, making introductions, before wide use of email or mobile phones. So, while a relatively short, if intensive, 3-month project, Weird View's design capitalized on close relations going back decades.

Our collective aim then was to capture the "memories and myths" associated with the terrace. This approach enabled some artistic license, and divergence from more formal social history methods enabling interpretation of the "behind closed doors" stories, from different perspectives.

Collaborating (facilitator-partner-foreigner-studentmultimedia designer)

A loosely ethnographic approach of "hanging out" including shooting video in the village generated interest, and sparked conversations in which we invited contributions of stories or memorabilia. Encouraging people to bring along and discuss family photos at informal get-togethers e.g. in the village pub, prompted shared reminiscences. For instance, Annie, a keen photographer, had recently moved to a residential home for the elderly and in her absence, her son participated on her behalf, bringing along Annie's three family photo albums that chronicled the terrace between the $40 \mathrm{~s}$ and the $60 \mathrm{~s}$; both a useful talking point and rich visual material. Over around 6-weeks the project grew rapidly as stories were recounted and collected, reenacted and captured using digital media. A certain "tipping point" was reached as locals offered anecdotes or other help (e.g. props for the videos), and the project grew well beyond a friends and family story.

Collectively, a core of community storytellers (including my partner) and the wider community generated dozens of reflective accounts of village life, which we artists retold in audio-visual and interactive media [40]. Around 60 individual stories were selected for the final exhibition, in consultation with Marie, who'd grown up on the terrace and informally took the role of community investigator (i.e. she was consulted on what should and should not be reproduced for the final work in the absence of more formal consent processes). Marie had initially shown interest as she was keen to discuss her new email account, and, as someone working with digital technology, I was invited along to 
trouble-shoot her network connection, in the process establishing very good relations.

We purposefully took a light touch approach to selecting the stories to develop for the artwork in a tactic to avoid potential tension. We rejected darker stories e.g. on domestic abuse or alcoholism, since I felt an acute personal responsibility to my partner, his family, friends and wider community. As non-Irish nationals and as artists, Valentina and I both worked inside, and also outside of the community [7] with our difference, and our use of digital tools, facilitating relations by attracting interest. For most of our community storytellers, Weird View was a first experience of being involved in a project using digital technologies and they were fascinated. While our objective did not include digitally up-skilling the community, the informal exchange of technical know-how - from troubleshooting email to learning the basics of shooting video - proved a by-product of mutual value which helped to quickly strengthen new relationships.

By the end of the project we had collectively produced a networked tapestry of the stories, realized in current and emergent digital media (circa 2000), in an interactive narrative form that spoke to the multivocality of a community, including the sometimes-conflicting accounts of the same event. The final piece aimed to invite interaction with an intertwined narrative snapshot of village life at a juncture when Co. Dublin was undergoing rapid urbanization.

\section{Moving on (memento maker-web master-former partner)}

The exhibition took place in the Douglas Hyde Gallery and, a week later the Muintir Na Tíre (local village hall) (Fig. 1). Our storytellers were invited to both, and turned out in force at the village hall. This event proved a fitting finalé to the project and comprised an informal evaluative process that elicited feedback and many further stories. Weird View won the annual Trinity prize and the exhibition curator expressed some interest in further developing the work. However, in the relative chaos that follows intensive postgraduate courses, we failed to find a continuation. I produced a website and CD-ROM, simplifying the dual touch-monitor installation for single screen $\mathrm{PC}$, as a memento for our storytellers. Developing the project as artists helped to open doors - as did working with the reputation of a renowned Irish university. Over its development, Weird View became an open exploration of community co-production in a project that was founded and reliant on both the newly available digital tools, and on the buy-in of the community for practices of community selfpresentation through digital media. The input of our storytellers was fundamental beyond even project conceptualization and pre-planning - through familial and community connections and experiences going back decades.

As I took a job in the multimedia industries in Dublin, my collaborator Valentina went on to develop more spatially distributed interactive narratives at the newly formed Media Lab Europe [41,42]. I later accepted a lecturing job in England while my partner chose to remain in Lucan.
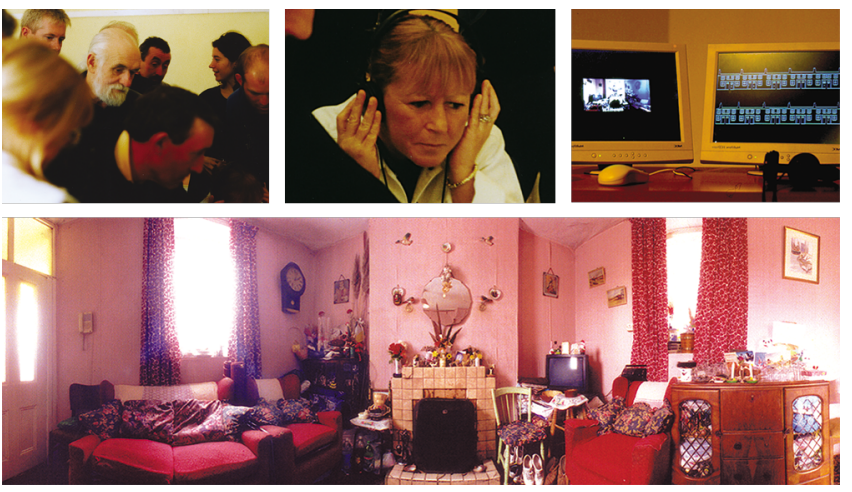

Fig 1. Top: Community storytellers watching Weird View in the Muintir Na Tíre and gallery installation. Bottom: Detailed view of one of the homes (photos: Jo Briggs and Tim Kovar).

\section{Democratising Technology (DemTech)}

Democratising Technology (www.demtech.qmul.ac.uk) was a research project that brought older people's community groups together with researchers to produce a generative, open-ended form of engagement with digital technology. We deliberately used arts methods to devise techniques that could be brought to bear on the design of our society and tools $[32,34,35]$. Informed by performance artist Lois Weaver's practice [49], she and I worked with participants' values and aspirations for the future, using performance development methods as a transformational tool to produce a workshop of techniques for engaging people to consider social values for future technologies. The project ran for 18 months from 2007-8 and included a series of events, in particular an exhibition, The Not Quite Yet (Fig 2.), at which several artworks based on the workshop research were shown, and also a public symposium 'On the Margins of Technology' about participation and older people.

Getting Started (an obsessive about connected products) DemTech was intended to link citizenship, technological futures, and people's sense of agency in participative ways, rather than tackle the design of specific artifacts. It grew from my obsession with what I called the social implications of networking everything, which I had been writing about for some time (e.g. [32]), and my background in drama. I wrote the bid when I worked as a design consultant and winning the grant helped propel me into an academic role. Lois and I used co-design methodology and arts theory on engagement $[5,33,34,49]$ to create a new path to democratically influencing the shape of future technology. We wanted to start with structures that seed ideas rather than introduce scenarios that would dictate themes. We wanted to work with people not already using networked technology. We chose to work with older people as a widely diverse cluster with low take-up of digital tools, but rich and varied experience of life, earlier technologies and ways of living. 


\section{Collaborating (co-developer-observer-interviewer)}

We sought experts on life experience, social relations and the ethics of technology. We recruited in the East End of London, around the university. Lois handled the outreach, explaining her approach to a range of community groups. The Geezers Club was one of the five groups that chose to be involved and about 10 of the Geezers (retired men) participated, allowing us to visit them during their usual meeting time and work with them. As part of DemTech exercises [35], they looked back to tools they had used in their lifetime and made up potential technologies. Inventions ranged from a teleporting device to magic money to a virtual holiday. But the striking development in this group was the will to reuse old skills and knowledge and to innovate in the field of renewable technology.

During the project, my role was to work closely with Lois to create activities that placed performance methods at the heart of imagining a networked future [34]. I observed workshops and analyzed our impact from each encounter. Lois' methods are devised to build confidence and silence self-criticism. It was evident that achieving these goals was essential to the collaboration and to fostering participants' sense of agency and articulacy.

As well as developing these methods with our community partners, we commissioned artists to work with the material generated in the workshops and to continue community liaison once the first phase finished. Each was briefed to create a piece of work for display as part of the DemTech exhibition The Not Quite Yet with one community group as partner. The goal was to learn more about aspects of artistic practice that support confident participation in digital design decisions. I was there to observe developments and analyze approaches, with a brief to see how arts work could support learning about and interacting with technology.

All three artists were known for creating work exploring power and participation, but how this comes out in their practice is different. We expected this to affect outcomes, noting one artist's practice was community-driven and collaborative, whereas another worked in live art, using her body, and the third used art in a conceptual way to critique digital culture. Conditions did not make exact comparison possible, but I could see the commitments of the artists made a difference [34]. Loraine Leeson, working with The Geezers, used approaches from conflict resolution, which include identifying what everyone involved wants and building on that. The project they co-devised concerned using lost skills to make a water turbine [34].

\section{Keeping in touch (documenter-friend-believer)}

Eight years after DemTech ended, The Geezers were still working on the legacy of their engagement with it. There was a redirection of effort in the community group towards inventing the turbine technology they had imagined in work for the show (Fig 2). When the project funding ran out, their initiative gained new adherents and new pots of money. They have continued to contribute to new turbine- related activities, in collaboration with an art gallery, a couple of charities, a secondary school, a barge-based restaurant and a social housing association, and drawn in professional engineers as well as further academics. They also worked with me again on a later project about participation. Although no design exercises towards specific ends were part of DemTech, what eventually emerged was a design for a fully-fledged water turbine from a community of ad hoc innovators, including and focused on The Geezers.

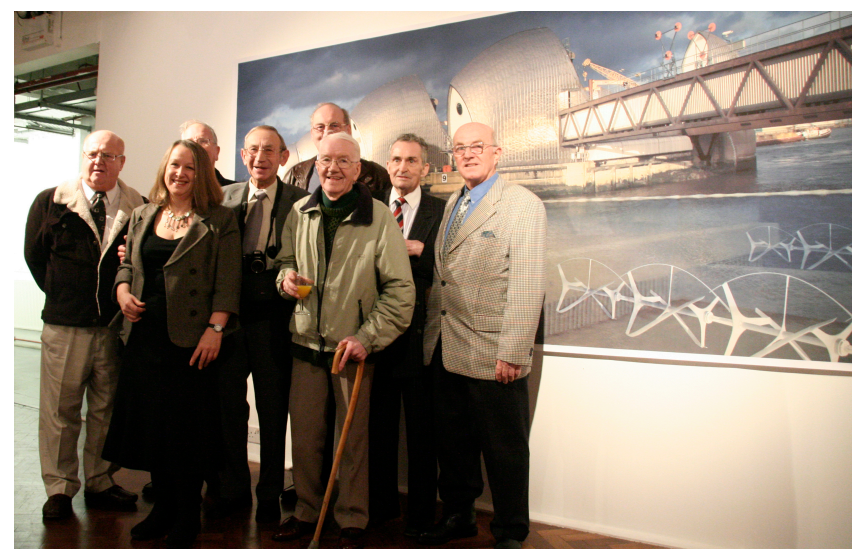

Fig 2. Socially engaged arts practitioner Loraine Leeson working with The Geezers in 2008 (photo: Jim Prevett).

I have continued to document this legacy, writing a history of the problems they encountered in getting the design tested [37]. But, in October 2014, a prototype water turbine was launched at a party on a barge in The Thames outside the British Houses of Parliament. I was there. It coped with the tides and worked for a short while. Then it broke.

The next iteration of turbine is being planned. I continue to be loosely involved, spotting funding opportunities and helping write applications, and will hope to see the Geezers I know at the next party, if they continue to keep well. Meanwhile, Loraine and I, who met through the project, will see each other for supper and I will catch up on the news, as she is still working closely with them.

Everyone agrees that the turbine - and its potential as a low-cost open-source energy generation tool - would not have come to pass were it not for DemTech. But equally the project cannot claim to have generated and sustained this secondary research activity and, despite the original focus, there was no special emphasis on the digital in the turbine work. Yet it seeded it. I have records of the men talking about their lost skills and their interest in being useful, in the housing situation along The Thames and what will power the new buildings. These conversations were held in the context of investigating values for future living and developing intervention methods. Lois elicited the sense of agency necessary to take action [35]. Loraine channeled the desire to act into a more structured form and has continued to steward them [37]. 10 years since getting the grant, I am enjoying the fulfillment of my vision that socially engaged 
art can have a meaningful, open-ended role in promoting participation in design and shaping future technology.

\section{Photo-parshiya}

The Photo-parshiya project took place between 2011 and 2014 and included a series of photography and design workshops, the creation of a bespoke digital artifact and pop-up exhibition involving staff and volunteers at an international women's center. Our focus was to bring people together to reflect on the role of technology for the presentation of excluded voices within institutional archives. The project was motivated by the desire to inform, over the long term, future digital tools and services that could benefit charitable organizations seeking to work with the cultural and heritage sectors.

\section{Getting Started (artist-researcher-volunteer)}

My involvement began when, as a new $\mathrm{PhD}$ researcher and new to HCI, I followed up on my interest in working with women who were born in South Asia, who had children and who had settled in the UK. The Center is an explicitly black feminist organization which values using the arts in the holistic support for immigration, employment advice, training, legal representation and therapeutic counseling for domestic violence. The Center's values and interests aligned with mine, which was informed in part by my previous experience of working as a SEA artist exploring online representation with women living in the UK who were born in South Asia and the Middle East. I introduced myself at the Center as an artist-researcher who was working with technology and showed staff and volunteers work I had produced before I started the $\mathrm{PhD}$ and also examples of digital prototypes from my research lab. I felt this was important to give them a sense of where I was coming from culturally, and to see how these artifacts were evaluated by people at the Center. Most importantly, this process helped to build trust, but also served to distinguish me from other researchers, who were seen by many staff and volunteers to extract from and not contribute to the values of the organization. I proposed to become a volunteer attending training and weekly meetings developing a series of informal drop-in arts workshops. This helped to discover people's interests and their existing use and experiences of digital technology and meanwhile to write a suitable ethics and confidentiality procedure that worked across institutions.

\section{Collaborating (facilitator-confidant-analyst-broker-designer)}

Focusing on creative making in the art sessions opened up a reflective space for women in which they felt able to more freely talk to one another. The women would often describe to each other and me, as facilitator, particular personal challenges that they were facing, and some of the tensions that they faced in building trusted networks within their neighborhoods and wider communities. In this sense the volunteering helped to re-define my initial focus from family connections, to how technology could support connections within and across the communities of women who came to the Center. At the same time, staff were also taking steps to develop a heritage project and we brought our interests together to develop a plan.

Given the diversity of experiences, cultures and ages of those who worked at the Center and accessed its services, I discussed with staff and volunteers a potential emphasis on photography. I had noticed particular tensions around visibility and how it was negotiated between people, in that there was a desire from some staff and volunteers to expose systems of injustice while also encouraging the women to take ownership for and crediting their contributions in making public the challenges they faced. However, there was also a growing nervousness about a collective online presence as the process of recording, archiving and reflecting on the work achieved raised issues around selfesteem and low confidence. Many women were learning English as an additional language while also, in some cases, accessing therapeutic support.

I then organized a series of structured workshops working with a small group, exploring how women were presenting themselves digitally, and where images were stored and shared, by the Center and across their trusted networks. I acted as a broker, moving between meetings with staff and volunteers and the workshops, which the women fitted in around their existing training and support. I tried to ensure everyone was kept informed, mapping out insights as they emerged and sharing these each week to further inform discussions and next steps.

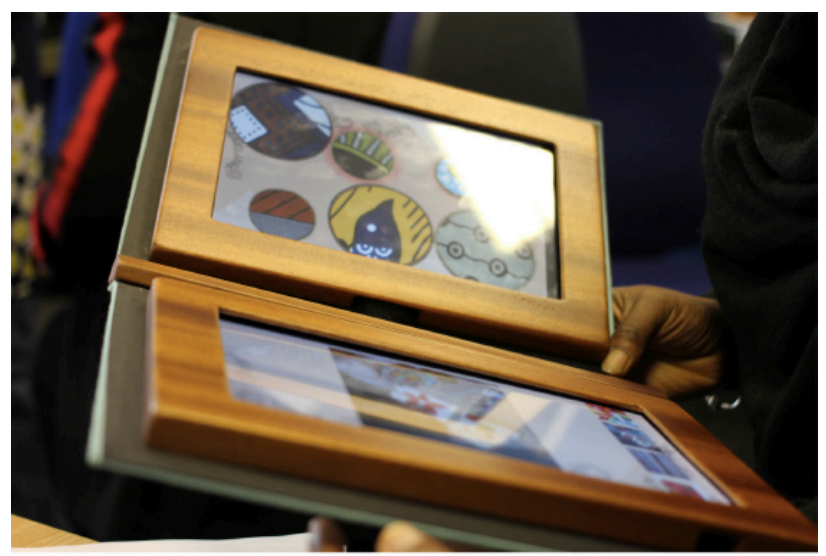

Fig 3. Photo-parshiya; digital photo-album used as an alternative social and material archive for minority ethnic and refugee women's representation in heritage and photography workshops and pop-up exhibition (photo: Lalya Gaye)

During this time I informally discussed these insights, maintaining confidentiality, with my supervisors, and software developers in the lab to work towards a design that could respond to the sensitivities, desires and concerns of the women. There was a balance here; respecting the women's privacy and maintaining anonymity, while communicating but not overwhelming the developers with the complexity of the women's lives, nor focusing on a technological solution. From these conversations I created design sketches and discussed these with staff and 
volunteers. However, when the Center relocated to another building we re-evaluated the project, coming up with the digital photo-album idea in response to the new premises. Once developed (see Fig 3.), the artifact was installed for 4 months and used as part of a series of workshops run between me, staff and volunteers. Women created their own wireless necklaces that acted as a password key to give them control in adding or removing photographs to the album. In addition we held a pop-up exhibition and additional workshops with heritage professionals, to draw attention to the challenges of visibility, ownership and control in multi-cultural archives.

\section{Keeping in touch (advocate-critical friend-neighbor)}

While the use of the digital photo-album marked the official end of my PhD, I continued to contribute, feeding insights into a successful funding proposal developed by the Center to run a much larger project BAM Sistahood! I also presented to funders and negotiated, within my new role as a post-doctoral researcher, time to follow up project progress. As BAM Sistahood! is now concluding, my role has become more of a critical friend, available when specific advice is needed. I keep up to date with what's happening on the project through regular email bulletins, but also more informally I regularly see women who are still involved and have become neighborhood friends.

\section{DISCUSSION}

Community-based design presents an exciting challenge for $\mathrm{HCI}$, yet there is a risk that a reliance on traditional humancentered methods may struggle to engage with the complexities of these contexts. Methods that employ finite and discrete engagements aimed at iterative refinement, and a homogenous view of people as "users" for technology interventions that solve problems may assume well-defined problems, goals and needs [50]. Yet this way of involving people risks framing particular identities, in turn limiting people's potential to inform the design process. In contrast, we have reflected on artist-researcher roles in SEA, to acknowledge the messiness, diversity and inequality of social relations within a variety of community contexts. This has helped to sketch out and problematize researcher responsibilities, project legacies, and researcher-community relationships, emphasizing how interactions around digital technology can be understood as more nuanced.

With a turn towards HCI research with a social agenda, it has become yet more necessary to gain a rich understanding of the longer term potential for technology and its role in making change. Meanwhile, we are being forced into an awareness of unintended consequences, through, among other things, a sudden attention to the crisis in resources. Reflecting on projects longitudinally means we can potentially see the social import of our actions. We could design for the short-term and make successful tools for the current moment, or we can vary our practices to respond to sites of investigation with genuine reciprocation and learning. Legacies are not always the successful use or adoption of the technologies themselves [45], but can include an understanding of the social processes that take place around the technology and connected to it This requires reflection on what is valued as part of our involvement and what persists when we move on.

We have detailed our particular approaches in how we have been open to understanding where a group or community is, where it wants to be and where it possibly could be in the future. In exploring futures together we did not achieve this through working with methods at a distance. We did so through sharing both our personal and professional values, and becoming involved as people, not in a narrowly and statically defined role such as "design researcher" or "ethnographer". Rather, we have mapped tentative steps, a willingness to accept a certain lack of control, and a sensitivity to existing structures and interests. In short we have taken a more humble position, that has moved us away from presuming that, through research alone, we may know how or indeed have the resources or ideas to make situations better, but rather, focused on questioning what better might mean with the communities with whom we have worked [39]. This has required us to adopt and encourage a critical openness to accept a multiplicity of roles and respond over time. We now sketch characteristics of critical openness that we have collectively found as useful orientations, in response to our case studies; responsibility and care, valuing relationships, and working openly with complexity.

\section{Responsibility and care}

While it may seem obvious to suggest that we take ethical and moral responsibility for our research when we have initiated and designed interventions, we mean something particular here. "Parachuting in" is the term used for work where researchers do not take the time to acquaint themselves with the lie of the land before seeking to offer alternatives. In the case studies, the flexible nature and indeterminate way that aspects evolved, meant that time became an important factor. We took time and built in practical ways to reflect and discuss emergent ideas and uncertainties and became flexible because we cared about how this work would be potentially meaningful for those involved. Flexibility, that is to go with the flow, was important in how we planned and designed our projects. But this also required commitments beyond what was initially planned, through shifts and expectations in our roles and responsibilities. In the case of Weird View artists were family friends and creative professionals and required responsible action for maintaining personal relationships. In DemTech, researchers were facilitators and then became documenters and friends, in the Photo-parshiya project the researcher moved from artist to volunteer to neighbor.

In the DemTech project, the artists who collaborated to create exhibitions did so in more socially oriented ways in order to listen to what was important for those involved. In doing so this seeded alternative opportunities for the group 
to explore their own concerns beyond the timeframe of the research project. What was sustained here went beyond the successful implementation of technology, and how it was adopted. What began to emerge, was how some of those involved were seeing themselves differently, and therefore taking on different roles in society. In the case of the Geezers, this was pronounced: they became the designers and researchers and even challenged dominant models of innovation. The project didn't focus on teaching skills to do this, but highlighted a process that encouraged confidence, so much so that 8 years after the project finished the group is continuing to iterate on their designs.

In this sense projects and researchers roles are of their time, situated in particular historical, cultural and research paradigms while being sensitive to subtle social changes as they take place over extended periods of time. Each project has needed this time for reflection, both during the projects themselves but also at a critical distance, in allowing time to pass and for further reflection to take place. This all points to ways of taking responsibility beyond the processes of intervention, and to investments in the processes of care in relationships. Staying in touch with people is key to understanding how effects of the project "may outlast their presentation' [23 p.23] beyond the immediate use of artifacts.

\section{Valuing relationships}

With our backgrounds in SEA practice and working with practitioners, we have recognized how important social connections are considered meaningful and situated in the context of the particularities of the community. As others have argued [31], this is not of course, just one-way. There is also recognition of the potential impact of practitioner relationships within the community and the changes in self in taking on shifting roles and experiencing other perspectives. What is clear through a discussion of our case studies is that this requires committed involvement and significant amounts of reciprocity; give and take, building and maintaining friendships, spending informal time with people. These are elements that can often be considered not important for research, or at worst detrimental.

In Weird View this was most evident in the building of relationships with family members, followed by buy-in and involvement from the whole street. The informal exchange of sharing skills in email and digital media production, and the final distribution of the work within the community village hall, online and on CD-ROM, helped support the artists in achieving their goals. The artists were clear in this objective when introducing the ideas. This project spoke to the value of intensive working with a community, exploring stories in complex and sometimes contradictory ways, showing the value in bringing people together to explore a particular place at a particular moment in time. This includes emotional investment (good feelings, anxieties, willingness to oblige and commit to certain propositions as part of valuing those relationships as well as associated responsibilities) and the tangled knots of 'engagement, affect, inequality' [4 p39] that being involved necessitates. There is a genuine hope that people will get something out of it and an honesty that, as artists and researchers, we get something out of it too. This is not just the papers and the reports or even the final exhibitions - but also how we care and how responsible we might feel when things go well and when they do not. Our case studies show how researchers and practitioners adapt to roles within the communities, which requires a particular kind of openness. This resides in the process not in the outcome and is more of an attitude, a willingness to engage and commit to people. This is what marks the path of such approaches rather than a commitment to particular methods or technology.

\section{Working openly with complexity}

As technologies are increasingly pervasive and immersive, we need means to anticipate the reception that changes will have. In our case studies, our long-term and/or intensive engagement saw a willingness to travel with people in ways that were meaningful for the communities and gave insight into their values and hopes. In DemTech and the PhotoParshiya project, we saw thematic moves, in prioritizing local responses that potentially jeopardized the original research goals. Inevitably, this can result in compromise and a need to justify reorientation in technologically intensive institutions focused on innovation of products and services. Nonetheless, insight and change came from not trying to tidy up contradiction and uncertainty but finding ways to work with it. If our goal is to understand the changing nature of human-computer relations, then we must be willing to be occasionally surprised.

In fact, we suggest that attention to complexity within community-based design requires a criticality that is an alternative to critical design or critical theory [2]. We prefer to frame criticality in terms of critical thinking as a practice that is not bound by rational or adversarial argumentation but is more closely connected to practical wisdom found in sharing stories of personal experience $[25,38]$. It exists in cultivating plurality in telling stories and collectively thinking of other endings. Our proposal is that criticality needs to be considered as a workable and mutable set of orientations guided, in part, by listening with communities.

In the case of Weird View, there was a critical commitment that aligned with the possibilities provided by experimentation with new digital forms of grass-roots broadcast and visual presentation. The artists created a multivocal form of work that spoke to the intimate topography and sociability of community they found, as a counter to formal media narratives bound by linear broadcast. The use of digital technology here helped to find a vocabulary that spoke to the sensitivities of this particular community as closely coupled with place, social identity and geography.

More than 10 years later, the Photo-parshiya project also embraced the polyvocal nature of digital representation, 
benefiting from the more recent developments in networked mobile technologies. This allowed for the co-creation of a digital mobile archive that enabled immigrant women often excluded from presentation and identification with official archives, to be included, so as to make sense of their individual and collective contributions. Criticality here meant paying attention to different concerns and sensitivities and asking what was at stake in sharing images and stories. It is interesting to ask too, whether the digital tools available at the time of the engagement impacted on the communities by enabling a different quality of relationship with the materials produced. We might hazard a guess that the social circumstances around the production of the materials and the style of intervention had more overall impact. Though the critical openness of SEA was present in both, the time scale alone dictates that relations would be different.

By contrast, DemTech embodied a questioning of humantechnology relations at its core and sought to make this a feature of the project work. Light was working to reveal "the "designed" therefore "designable" nature of tools and systems' as part of the method [35 p2242]. The project worked to enfranchise marginalized groups (in this case, older people) by finding their confidence and authority in a territory that, at best, often treats them as irrelevant. Critical practice is here very much a creative practice, seen particularly in this last example, where, beyond coconstruction, communities set off to change the world on their own terms.

\section{Being socially engaged within community}

In taking on these cultural challenges and the complexity of social process that necessarily accompanies them, we do not create straightforward projects and hence we do not create straightforward narratives in describing the research process. Working with and honoring the complexity and the messiness of the processes involves a critical commitment not to produce clean accounts of data collection to be enacted or described as distinct methods away from the relationships in which they were developed. This eschewal may include attention to relational aspects of risk taking, negotiation, uncertainty and compromises, as emerging critical awareness and feelings of ownership change.

We propose that SEA can be appreciated as a set of metaapproaches that underline the interpersonal and relational at a scale that is much more human, for all its partiality. This is the core commitment. Criticality is therefore enacted, not as intellectual argumentation or slick design, but as a process of constant questioning, through improvisation, opportunism, and adaptation. Rather than relying on ways of doing that are already pre-formed, comfortable and which give neat results for research, SEA emphasizes responsiveness to immediate and enduring local concerns. As has been shown here, this has the potential to create lasting benefits for those involved and change in deepseated relational aspects (across social, technical and economic systems), many of which show emancipatory effects. Yet this also requires commitments of time, not only within the formal timescales and roles written into project proposals, but into unknown futures of the communities we work within and our own.

\section{CONCLUSION}

As HCI increasingly seeks to design research in socially responsive ways, alternative approaches are valuable both to deliver new insights for development and to show the merit of different styles of engagement. While practices from SEA have been adopted across sustainability and the arts more generally to raise critical questions, the relational, empathic and community-based orientation of such work has sometimes been lost. The approach to engagement we have demonstrated here is not an add-on but fundamental to open-ended inquiry. In presenting case studies where SEA practitioners and researchers have worked with technology to raise questions about future design and use, taking time, responsibility and care, valuing relationships and working openly with complexity were key commitments. We do not suggest that such practices replace other forms of inquiry. Indeed there are many researchers working with similarly sensitive, engaging processes in relevant work in this area. What we have sought to show is that SEA approaches and their related understanding of human-computer relations can augment and inform community-based design as it is currently understood within HCI. They can support work in contexts where cultural issues and/or social structures are paramount, raise awareness of tolerances and capacities to complement work that is more quantifiable. Many of these insights are only to be discovered in building and exploring slower, invested and meaningful connections.

\section{ACKNOWLEDGMENTS}

We would like to thank all our collaborators including our community storytellers and Valentina Nisi (Weird View), Pat Healey, Gini Simpson, Lois Weaver, Lorraine Leeson and the Geezers (DemTech) plus volunteers and staff at the Angelou Center (Photo-parshiya). Publication of this paper was supported by RCUK EPSRC grant no: EP/K037366/1.

\section{REFERENCES}

1. Liam J. Bannon and Pelle Ehn. 2013. Design: Design Matters in Participatory Design in Jasper Simonsen and Toni Robertson (Eds.) Routledge International Handbook of Participatory Design, London and New York: Routledge. 37-63.

2. Jeffrey Bardzell, and Shaowen Bardzell. 2013. What is "critical" about critical design? In Proceedings of the SIGCHI Conference on Human Factors in Computing Systems (CHI '13), 3297-3306.

DOI: http://doi.acm.org/10.1145/1978942.1978979

3. Shaowen Bardzell and Jeffrey Bardzell. 2011. Towards a feminist HCI methodology: social science, feminism and HCI. In Proceedings of the SIGCHI Conference on Human Factors in Computing Systems (CHI '11), 675684. http://doi.acm.org/10.1145/1978942.1979041 
4. Claire Bishop. 2012. Artificial Hells: Participatory Art and the Politics of Spectatorship. Verso Books, UK.

5. Augusto Boal. 1979. Theatre of the Oppressed. London: Pluto Press

6. Jo Briggs 2012. 'Weird (Re)View : Informing qualitative HCI methods? Reflections on a personal participatory arts project.' In: 'Perspectives on Participation' workshop in association with DIS' 12. https://openlab.ncl.ac.uk/participation/activities/dis201 2/

7. Jo Briggs, Celia Lury and Sarah Teasley. 2015. Creative Temporal Costings: A collaborative study with Leeds Creative Timebank. AHRC ProtoPublics Research Report.

http://nrl.northumbria.ac.uk/24800/1/CTC_research_ report_online.pdf

8. Hrönn Brynjarsdóttir Holmer, Carl DiSalvo, Phoebe Sengers and Thomas Lodato. 2015. Constructing and constraining participation in participatory arts and HCI. In Int. J. Hum.-Comput. Stud. 74: 107-123 (2015). doi:10.1016/j.ijhcs.2014.10.003

9. Judith Butler. 1990. Gender Trouble. London: Routledge.

10. John M. Caroll and Mary Beth Rosson. 2013. Wild at Home: The Neighborhood as a Living Laboratory for HCI. ACM Trans. Comput.-Hum. Interact.20, 3, Article 16 (Jul 2013).

http://dx.doi.org/10.1145/2491500.2491504

11. Rachel Clarke, and Peter Wright. 2012. Evocative of experience: crafting cross-cultural digital narratives through stories and portraits. In Proceedings of the 7th Nordic Conference on Human-Computer Interaction (NordiCHI '12) 318-321. http://doi.acm.org/10.1145/2399016.2399066

12. Rachel Clarke, Peter Wright, Madeleine Balaam and John McCarthy. 2013. Digital portraits: photo-sharing after domestic violence. In Proceedings of the SIGCHI Conference on Human Factors in Computing Systems (CHI '13) 2517-2526.

http://doi.acm.org/10.1145/2470654.2481348

13. Rachel Clarke, Jo Briggs, Ann Light, Sarah Heitlinger and Clara Crivellaro. 2014. Socially engaged arts practice in HCI. In CHI '14 Extended Abstracts on Human Factors in Computing Systems (CHI EA'14) 69-74. http://doi.acm.org/10.1145/2559206.2559227

14. Rachel Clarke, Paul Dunphy and Peter Wright. 2015. Photo-parshiya: Discursive Assemblages in an International Women's Center. In Proc. Research through Design (RtD '15) available at http://figshare.com/articles/RTD2015_08_Photo_parshi ya_Discursive_Assemblages_in_an_International_Wo men_s_Center/1328007
15. Carl DiSalvo, Kirsten Boehner, Nicholas A. Knouf and Phoebe Sengers 2009. Nourishing the ground for sustainable HCI: considerations from ecologically engaged art. In Proceedings of the SIGCHI Conference on Human Factors in Computing Systems (CHI '09), 385-394. http://doi.acm.org/10.1145/1518701.1518763

16. Carl DiSalvo, Andrew Clement and Volkmar Pipek. 2013. Communities: Participatory Design for, with and by communities. In Jasper Simonsen and Toni Robertson (Eds.) Routledge International Handbook of Participatory Design, London and New York: Routledge. 182-209.

17. William H Dutton, and Grant Blank. 2011. Next Generation Users: The Internet in Britain. Oxford Internet Survey 2011. Oxford, UK: Oxford Internet Institute, University of Oxford.

18. Sarah Fox and Christopher Le Dantec. 2014. Community historians: scaffolding community engagement through culture and heritage. In Proceedings of the 2014 conference on Designing interactive systems, (DIS'14) 785-794. http://doi.acm.org/10.1145/2598510.2598563

19. Paulo Freire, 1970. Pedagogy of the Oppressed. New York, Continuum.

20. Alison Gilchrist. 2009. The well-connected community: A networking approach to community development. Bristol, Polity.

21. Donna Haraway. 1988. Situated Knowledges. The Science Question in Feminism and the Privilege of Partial Knowledge. Feminist Studies, Vol 14, No 3:575-599.

22. Gillian Hayes. 2011. The relationship of action research to human-computer interaction. ACM Trans. Comput.-Hum. Interact. 18, 3, Article 15 (Aug 2011). http://dx.doi.org/10.1145/1993060.1993065

23. Pablo Helguera. 2011. Education for Socially Engaged Art: A materials and technique handbook. Jorge Pinto Books, US.

24. Larissa Hjorth and Kristen Sharp. 2014. The art of ethnography: The aesthetics or ethics of participation? Visual Studies 29: 2, 128-135.

25. bell hooks. 2010. Teaching critical thinking: Practical wisdom. Routledge.

26. Helena Karasti, Karen S. Baker and Florence Miller. 2010. Infrastructure Time: Long-term Matters in Collaborative Development. CSCW Vol 19, Issue 3:377-417. doi:10.1007/s10606-010-9113-z

27. Grant Kester. 2004. Conversation Pieces: Community and Communication in Modern Art. University of California Press, US.

28. Miwon Kwon. 2002. One Place After Another: site specific art and locational identity. MIT Press. 
29. John Law and Annemarie Mol (Eds.). 2002. Complexities: Social Studies of Knowledge Practices. Duke University Press.

30. John Law. 2004. After Method: Mess in Social Science Research. Routledge.

31. Chris Le Dantec and Sarah Fox. 2015. Strangers at the Gate: Gaining Access, Building Rapport, and CoConstructing Community-Based Research. In Proceedings of the 18th ACM Conference on Computer Supported Cooperative Work and Social Computing (CSCW'15), 1348-1358. http://doi.acm.org/10.1145/2675133.2675147

32. Ann Light. 2002. Users as Designers- Challenge of the Network Age (08 May 2002), Usability News.

33. Ann Light, Lois Weaver, Pat Healey and Gini Simpson. 2008. Adventures in the Not Quite Yet: using performance techniques to raise design awareness about digital networks. In. Undisciplined! Design Research Society Conference 2008 (DRS'08).

34. Ann Light, Gini Simpson Lois Weaver and Pat Healey. 2009. Geezers, Turbines, Fantasy Personas: Making the Everyday into the Future. In Proceedings of Creativity and Cognition 2009, 39-48. http://doi.acm.org/10.1145/1640233.1640243

35. Ann Light. 2011. Democratising Technology: Inspiring Transformation with Design, Performance and Props. Proceedings of the SIGCHI Conference on Human Factors in Computing Systems (CHI'11) 2239-2242. http://doi.acm.org/10.1145/1978942.1979269

36. Ann Light and Yoko Akama. 2012. The human touch: participatory practice and the role of facilitation in designing with communities. Proceedings of the $12^{\text {th }}$ Participatory Design Conference (PDC'12). 61-70 http://doi.acm.org/10.1145/1978942.1979269

37. Ann Light. 2014. Citizen Innovation: ActiveEnergy and the Quest for Sustainable Design, in Boler, M. and Ratto, M. (Eds.) DIY Citizenship: Critical Making and Social Media. MIT Press

38. John McCarthy and Peter Wright, P. 2015. Take [A]part: The Politics and Aesthetics of Participation in Experience-centerd Design. MIT Press.

39. Annemarie Mol. 2008. The logic of care: Health and the Problem of Patient Choice. Routledge.

40. Valentina Nisi and Mads Haahr. 2004. Weird View: Interactive Multilinear Narratives and Real-Life Community Stories' in Crossings: eJournal of Art and Technology 4.1, Dec 2004.

41. Valentina Nisi, Ian Oakley and Mads Haahr, 2006 Inner City Locative Media: Design and Experience of a
Location- Aware Mobile Narrative for the Dublin Liberties Neighborhood, Intelligent Agent 6 (2).

42. Valentina Nisi, Alison Wood, Glorianna Davenport and Ian Oakley, 2004. Hopstory: An interactive, location-based narrative distributed in space and time. Technologies for Interactive Digital Storytelling and Entertainment pp132-141.

43. Gillian Rose. 1997. Situating knowledges: positionality, reflexivities and other tactics. Progress in Human Geography. June 1997, Vol. 21 No.3: 305-320. doi: 10.1191/030913297673302122

44. Arnd Schneider and Christopher Wright (Eds.). 2010. Between Art and Anthropology. Contemporary Ethnographic Practice. Berg Press.

45. Nick Taylor, Keith Cheverst, Peter Wright and Patrick Olivier. 2013. Leaving the wild: lessons from community technology handovers. In Proceedings of the SIGCHI Conference on Human Factors in Computing Systems (CHI '13), 1549-1558. http://doi.acm.org/10.1145/2470654.2466206

46. Alex Taylor, Siân Lindley, Tim Regan. David Sweeney, Vasillis Vlachokyriakos, Lillie Grainger and Jessica Lingel. 2015. Data-in-Place: Thinking through the Relations Between Data and Community. In Proceedings of the SIGCHI Conference on Human Factors in Computing Systems (CHI '15) 2863-2872. http://doi.acm.org/ 10.1145/2702123.2702558

47. Tenantspin http://superflex.net/activities/2002/05/01/superchannel _-_tenantspin

48. John Vines, Rachel Clarke, Peter Wright and Patrick Olivier. 2013. Configuring participation: on how we involve people in design. Proceedings of the SIGCHI Conference on Human Factors in Computing Systems (CHI '13) 429-438. http://doi.acm.org/10.1145/2470654.2470716

49. Lois Weaver. 2007. Make Something: a manifesto for making performance about making change. In Elaine Aston and Sue-Ellen Case (Eds). Performing Global Feminisms. Basingstoke, UK: Palgrave Macmillan.

50. Peter Wright. 2011. Reconsidering the $\mathrm{H}$, the $\mathrm{C}$ and the I: Some Thoughts on Reading Lucy Suchman's Human-Machine Reconfigurations. interactions 18, 5 (September 2011), 28-31. DOI=http://dx.doi.org/10.1145/2008176.2008185

51. Peter Wright and John McCarthy. 2010. Experience Centerd Design: Designers, Users and Communities in Dialogue. Morgan \& Claypool: USA. 